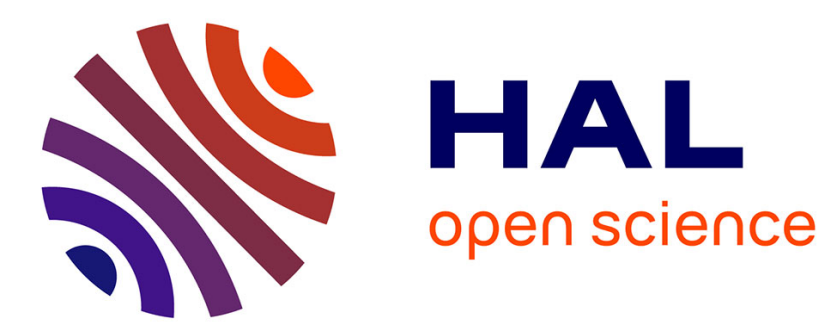

\title{
Chromic acid dealumination of zeolites
}

\author{
Viktoria Babić, Siddardha Koneti, Simona Moldovan, Maxime Debost, \\ Jean-Pierre Gilson, Valentin Valtchev
}

\section{To cite this version:}

Viktoria Babić, Siddardha Koneti, Simona Moldovan, Maxime Debost, Jean-Pierre Gilson, et al.. Chromic acid dealumination of zeolites. Microporous and Mesoporous Materials, 2022, 329, pp.111513. 10.1016/j.micromeso.2021.111513 . hal-03423467

\section{HAL Id: hal-03423467 https://hal.science/hal-03423467}

Submitted on 10 Nov 2021

HAL is a multi-disciplinary open access archive for the deposit and dissemination of scientific research documents, whether they are published or not. The documents may come from teaching and research institutions in France or abroad, or from public or private research centers.
L'archive ouverte pluridisciplinaire HAL, est destinée au dépôt et à la diffusion de documents scientifiques de niveau recherche, publiés ou non, émanant des établissements d'enseignement et de recherche français ou étrangers, des laboratoires publics ou privés. 


\title{
Chromic acid dealumination of zeolites
}

Viktoria Babić,, Siddardha Koneti, ${ }^{2}$ Simona Moldovan, ${ }^{2}$ Maxime Debost, ${ }^{1}$ Jean-Pierre Gilson, ${ }^{1}$ Valentin Valtchev ${ }^{1}$,

${ }^{1}$ Normandie Université, ENSICAEN, UNICAEN, CNRS, Laboratoire Catalyse et Spectrochimie, 14000 Caen, France

${ }^{2}$ Institut des Sciences Appliquées de Rouen, Université de Rouen, Groupe de Physique des Matériaux (GPM), 76801 Rouen, France

\begin{abstract}
Commercial zeolites with CHA, MFI, and LTL framework topology are subjected to acid treatment with chromic acid $\left(\mathrm{H}_{2} \mathrm{CrO}_{4}\right)$ solutions with concentrations ranging between 0.1 and 10 $w / \%$. As chromic acid forms polymeric species as a function of concentration, specific effects were obtained with these three zeolites, differing by their framework topology, pore size, Si/Al ratios and crystal size. The etched zeolites are characterized by X-ray diffraction, SEM, TEM, $\mathrm{N}_{2}$ physisorption, ICP-AES, ${ }^{27} \mathrm{Al}$ and ${ }^{29} \mathrm{Si}$ MAS NMR, ${ }^{29} \mathrm{Si}\left\{{ }^{1} \mathrm{H}\right\}$ cross-polarization spectra, EDX. Their acidic properties are probed with pyridine and $d_{3}$-acetonitrile by in situ FTIR. Results indicate that the $8 \mathrm{MR}(\mathrm{CHA})$ and $10 \mathrm{MR}(\mathrm{MFI})$ zeolites are more resistant to acid treatment with chromic acid than the 12 MR (LTL) zeolite. This paves the way for rational control of zeolite dealumination since adjusting chromic acid concentration will generate anions appropriate for treating a particular zeolite.
\end{abstract}




\section{KEYWORDS}

hierarchical zeolites; chromic acid; CHA

\section{Introduction}

Dealumination by acid leaching is one of the earliest methods used for the demetallation of zeolites. Removing aluminum from a zeolite framework was first reported by Barrer and Makki in 1964 on clinoptilolite by refluxing in hydrochloric acid.[1] Later on, different types of acids and treatment conditions were used to control zeolite dealumination.[2]

The extent of dealumination depends on the zeolite structure type and the aluminum position in the framework. In certain zeolites, the majority of the aluminum in the framework can be removed, thereby enhancing their hydrophobicity and hydrothermal stability.[3] For example, aluminum can be completely removed from pentasil-type zeolites.[4-6] Dealumination produces also defect sites referred to as "hydroxyl nest" (silanol nest), as four SiOH groups are generated per one Al removed.[2] However, higher concentrations of framework defects are detrimental to the thermal stability of zeolites.[7,8]

One of the best-known examples is zeolite Y's (FAU-type) dealumination yielding an ultra-stable (US) zeolite Y derivative, a key component of modern cracking and hydrocracking catalysts.[3] Reducing the acid site density minimizes the extent of proton transfer reactions which results in increased olefin yield. Dealumination is an important tool to adjust zeolite's activity and selectivity in catalytic processes (e.g., octane barrels in Fluid Catalytic Cracking (FCC) or gasoline $v s$ middle distillate selectivity in Hydrocracking of heavy oil fractions). Hence to obtain 
a high-silica zeolite Y, i.e., ultrastable zeolite Y (USY), dealumination methods are beneficial, which in the case of zeolite $\mathrm{Y}$ is typically done by steaming.

Dealumination also leads to significant structure and porosity losses.[9] The loss of acid sites, creation of mesopores with broad range distribution, formation of inaccessible mesopores are important limitations of the dealumination process.[10] Van Nierkerk et al., for instance, found that dealumination by nitric acid was linked to a partial loss of mordenite's crystallinity.[4]

Through the years, post-synthesis dealumination of zeolites was extended to various mineral and organic acids. It is contemplated that the mineral acids solubilize silicon framework atoms more readily than organic acids, which contributes to losses of structural integrity.[9] Organic acids and complexing agents (EDTA, acetylacetone, tartaric and oxalic acids) have also been used successfully in zeolite dealumination.[7]

Chromium (VI) is a strongly oxidizing agent and exists only in oxo species $\mathrm{CrO}_{3}, \mathrm{CrO}_{4}{ }^{2-}$ and $\mathrm{CrO}_{2} \mathrm{~F}_{2}$.[11] $\mathrm{CrO}_{3}$ forms different ions in water; depending on the $\mathrm{pH}$ (concentration), chromate $\left(\mathrm{CrO}_{4}{ }^{2-}\right)$, dichromate $\left(\mathrm{Cr}_{2} \mathrm{O}_{7}{ }^{2-}\right)$, hydrogen chromate $\left(\mathrm{HCrO}_{4}^{-}\right)$, dihydrogen chromate (chromic acid, $\left.\mathrm{H}_{2} \mathrm{CrO}_{4}\right)$, hydrogen dichromate $\left(\mathrm{HCr}_{2} \mathrm{O}_{7}{ }^{-}\right)$, trichromate $\left(\mathrm{Cr}_{3} \mathrm{O}_{10}{ }^{2-}\right)$ and tetrachromate $\left(\mathrm{Cr}_{4} \mathrm{O}_{13}{ }^{2-}\right)$ are observed.[12-14] The last three occur in solutions of $\mathrm{Cr}(\mathrm{VI})$ concentrations $>1$ M.[12] The formula $\mathrm{H}_{2} \mathrm{Cr}_{n} \mathrm{O}_{3 n+1}$ can express polyacids or polyanions containing $\mathrm{Cr}$ (VI), but the value of $n$ is presumed not to exceed 4.[14,15] Chromium-oxygen multiple bonding $(\mathrm{Cr}=\mathrm{O})$ enables building a pattern of $\mathrm{CrO}_{4}$ infinite chains $\left(\mathrm{O}-\mathrm{CrO}_{2}-\mathrm{O}\right)$ having corner-sharing tetrahedra with only Van der Walls forces between the chains.[16-18] The structures of $\mathrm{CrO}_{4}$ oligomers determined for solid-state salts can be seen in Figure 1. 

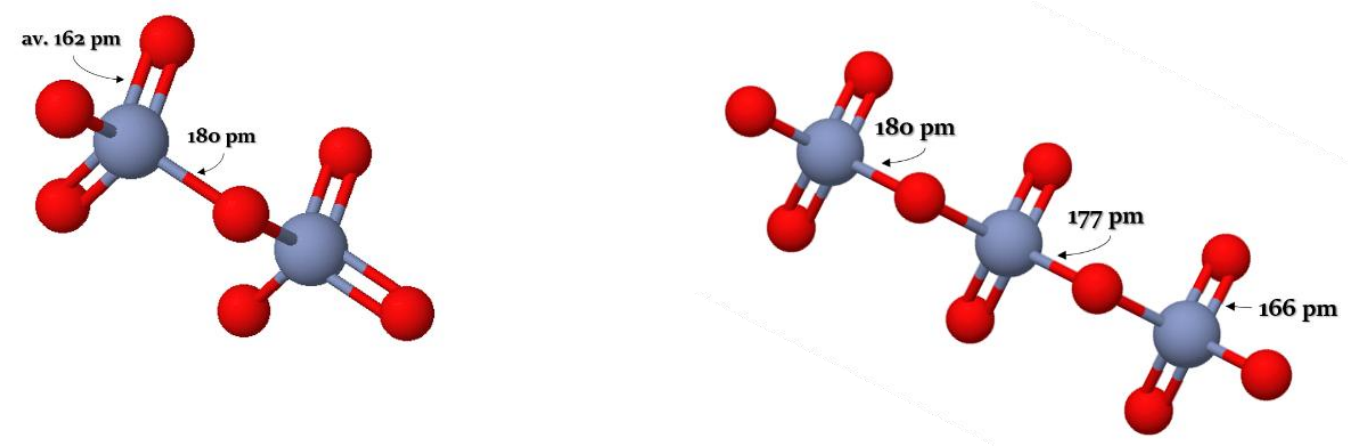

Figure 1. Structures of $\mathrm{Cr}_{2} \mathrm{O}_{7}{ }^{2-}$ (left) in 2-amino-5-nitropyridinium salt (from [19]) and $\mathrm{Cr}_{3} \mathrm{O}_{10}{ }^{2-}$ (right) in guanidinium salt (from [20]). Color code: Cr, blue; O, red.

The $\mathrm{pH}$ windows of chromium (VI) species can be divided as: i.) $\mathrm{pH} \leq 0$ where $\mathrm{H}_{2} \mathrm{CrO}_{4}, \mathrm{Cr}_{3} \mathrm{O}_{10}{ }^{2-}$ and $\mathrm{Cr}_{4} \mathrm{O}_{13}{ }^{2-}$ are dominant species, ii.) $\mathrm{pH}=2-6$ where $\mathrm{HCrO}_{4}{ }^{-}$and $\mathrm{Cr}_{2} \mathrm{O}_{7}{ }^{2-}$ occur simultaneously, and iii.) $\mathrm{pH}>6$, where $\mathrm{CrO}_{4}{ }^{2-}$ prevails.[13] However, the existence of $\mathrm{HCrO}_{4}{ }^{-}$is still a matter of debate since the ion is not detectable by spectroscopy.[18,21]

Chromium trioxide is used either alone or as an additive to other acids as an oxidizing agent in a variety of etching solutions. Specifically, $\mathrm{H}_{3} \mathrm{PO}_{4} / \mathrm{CrO}_{3}$ for oxide removal from $\mathrm{Al}_{2} \mathrm{O}_{3}$ or defect etching and cleaning of Si semiconductor wafers with $\mathrm{HF} / \mathrm{CrO}_{3} \cdot[22,23]$ However, its potential to dealuminate zeolites hasn't been studied so far. Its ability to form polyanions of different sizes and reactivity is a strong driver to use chromic polyacids to etch/dealuminate zeolites as further fine-tuning zeolite etching could lead to better zeolite crystal engineering of structures representative of industrially relevant small (CHA, $8 \mathrm{MR}$ ), intermediate (MFI, $10 \mathrm{MR})$ and large (LTL, 12 MR) zeolites.

\section{Experimental section}

\section{Preparation}


Commercially available SSZ-13 (ACS Materials), MFI-55 (Clariant), and LTL (Tosoh) are dealuminated by chromic acid. The $\mathrm{CrO}_{3}$ crystals are purchased from VWR, and fresh solutions are prepared just prior to the treatment. The parents in ammonium form, CHA (SSZ-13), MFI (MFI-55, ZSM-5), and LTL are dealuminated with $0.1,0.5,1,2,4$, and $10 w / \%$ solutions of $\mathrm{CrO}_{3}$, corresponding to $0.01,0.05,0.1,0.2,0.4$ and $1.0 \mathrm{~mol} / \mathrm{dm}^{3}$ chromic acid solutions.

Dealumination takes place at room temperature under gentle agitation. The liquid-solid ratio is 20 , and the treatment time $60 \mathrm{~min}$ for all reactions. Solely the LTL-0.1-30 sample is treated for 30 minutes.

After dealumination, the solids are recovered by filtration and washed thoroughly with double distilled water, dried overnight at $60{ }^{\circ} \mathrm{C}$, carefully ground, and ready for characterization.

All samples are labelled ZEOLITE-X, where ZEOLITE is the structure type (CHA, MFI or LTL), $\mathrm{X}$ is the mass fraction of chromic acid used. For example, $1 \mathrm{~g}$ of CHA mixed with 0.1 $w / \% \mathrm{CrO}_{3}$ at $25^{\circ} \mathrm{C}$ for 60 minutes is referred to as $\mathrm{CHA}-0.1$. The $\mathrm{CrO}_{3}$ concentrations ( $w / \%$, mass fractions) are $0.1,0.5,1,2,4$, and 10 . In the case of LTL-0.1-30 it is labelled with additional number to highlight its 30 minutes treatment.

\section{Physicochemical characterization}

The X-ray diffraction (XRD) patterns are recorded using a Malvern PANalytical X'Pert PRO Diffractometer with $\mathrm{CuK}_{\alpha}$ radiation $(\lambda=1.5418 \AA, 45 \mathrm{kV}, 40 \mathrm{~mA})$. The data are collected over a range of $4-50^{\circ} 2 \theta$ with a time per step of $0.0167^{\circ} \mathrm{s}^{-1}$ using a $1 / 4^{\circ}$ divergence slit. Relative crystallinity values of SSZ-13 samples are determined from the integrated peak areas between 20 and $32^{\circ} 2 \theta$ [24] and compared with their parent SSZ-13. Relative crystallinity values of MFI-55 samples are determined from the integrated peak areas between 23.1 and $24.3^{\circ} 2 \theta$ [25] and 
compared with their parent MFI-55. Relative crystallinity values are determined from peak area at $22.6-33.6^{\circ} 2 \theta$ for all zeolite $\mathrm{L}$ samples. The parent zeolite $\mathrm{L}$ is used as a reference sample.[26] Relative crystallinity is expressed as \% $\mathrm{RC}$.

The $\mathrm{N}_{2}$ physisorption isotherms are acquired on a Micromeritics 3Flex high-resolution surface characterization analyzer at $-196{ }^{\circ} \mathrm{C}$. About $100 \mathrm{mg}$ of the sample is degassed at $300{ }^{\circ} \mathrm{C}$ under vacuum overnight prior to the analysis. The isotherms are recorded using the MicroActiv 3Flex Adsorption Analyzer analysis program. Micropore volume ( $\left.V_{\text {micro }}\right)$ is evaluated from non-local DFT porosity distribution using a model of oxide surface with cylindrical geometry. The total pore volume $\left(V_{\text {tot }}\right)$ is determined by the amount of adsorbed nitrogen at $p / p_{0}=0.98$ using the Gurvich rule. Mesopore volume $\left(V_{\text {meso }}\right)$ is the difference between the total pore volume $\left(V_{\text {tot }}\right)$ and micropore volume $\left(V_{\text {micro }}\right), V_{\text {meso }}=V_{\text {tot }}-V_{\text {micro. }}$. The chemical composition of samples is determined by inductively coupled plasma atomic emission spectroscopy (ICP-AES) on an Agilent instrument AES 5100 VDV ICP; prior to analysis all the samples are digested in aqua regia and $\mathrm{HF}$ acid.

SEM micrographs are collected on a MIRA TESCAN scanning electron microscope (SEM) equipped with a field emission gun. Micrographic images are obtained under an acceleration voltage of $30 \mathrm{kV}$. Before measurement, samples are deposited on a sample holder with conductive adhesive tape and sputtered for $30 \mathrm{~s}$ with platinum.

Transmission electron microscopy (TEM) micrographs of LTL samples are taken on a JEOL ARM 200 CFeg Analytical TEM at $200 \mathrm{keV}$ using a high angle annular dark-field (HAADF) and bright field (BF) detector under Scanning TEM (STEM) mode. Prior to analysis, the samples are dispersed in ethanol by ultrasounds for 20-30 minutes before being transferred to a carbon 
support grid for measurements. EDX (energy-dispersive X-ray spectroscopy) is used to chart the elements and study the composition of samples. Elemental charting is carried out at $80 \mathrm{kV}$ electron beam in order to limit damage from the beam. The STEM mode is employed for both imaging and elemental charting using the DigiScan module from Gatan Digital Micrograph and the AnalysisStation software, respectively. Micrographs of CHA samples are collected High resolution transmission electron microscopy (HR-TEM) using a FEI LaB6 TECNAI G2 operated at $300 \mathrm{kV}$. Prior to the measurement, powder samples were ground in a mortar, added to a propanol solution. Liquid droplets were dropped onto a Ni microgrid, dried, and transferred to the standard holder.

${ }^{27} \mathrm{Al}$ and ${ }^{29} \mathrm{Si}$ MAS Solid-state NMR spectra are recorded on a Bruker Avance $400 \mathrm{MHz}$ spectrometer (magnetic field of $9.4 \mathrm{~T}$ ) using $4 \mathrm{~mm}$ zirconia rotors. ${ }^{27} \mathrm{Al}$ and ${ }^{29} \mathrm{Si}$ spectra are recorded with spinning speed of $14 \mathrm{kHz}$ and $12 \mathrm{kHz}$, respectively. The chemical shifts are referenced to a $1 \mathrm{~m} \mathrm{Al}\left(\mathrm{NO}_{3}\right)_{3}$ aqueous solution $\left({ }^{27} \mathrm{Al}\right)$ and TMS $\left({ }^{29} \mathrm{Si}\right) .{ }^{27} \mathrm{Al}$ MAS NMR of All MFI are recorded on a Bruker Avance $500 \mathrm{MHz}$ spectrometer.

Prior to the FTIR study, all samples are pressed into self-supporting wafers $\left(2 \mathrm{~cm}^{2}\right)$ and activated in situ at $450{ }^{\circ} \mathrm{C}$ for 2 hours under vacuum. The FTIR spectra (128 scans) are collected on a NICOLET 6700 fitted with a DTGS detector $\left(4 \mathrm{~cm}^{-1}\right.$ optical resolution). Pyridine is used to probe all sites in zeolites L and MFI-55; typically, a pressure of 1 torr pyridine is introduced in the cell to reach saturation. The wafer is then heated twice at $150{ }^{\circ} \mathrm{C}$ for 15 min to ensure a homogeneous distribution throughout the sample. Pyridine is then gradually $\left(50{ }^{\circ} \mathrm{C}\right.$ for $\left.10 \mathrm{~min}\right)$ desorbed in the temperature range of $50-200{ }^{\circ} \mathrm{C}$. All samples' weights are normalized to $20 \mathrm{mg}$. Brønsted (B) and Lewis (L) acid site concentrations are quantified using the $1545 \mathrm{~cm}^{-1}$ (B,

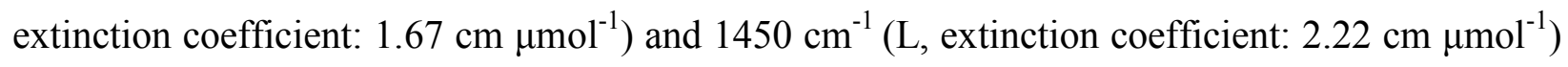


peaks after desorption at $150{ }^{\circ} \mathrm{C}$ for LTL samples and $200{ }^{\circ} \mathrm{C}$ for MFI samples.[27] SSZ-13 (CHA) samples are equilibrated for $15 \mathrm{~min}$ at room temperature with a pressure of 1 torr $d_{3^{-}}$ acetonitrile $\left(\mathrm{CD}_{3} \mathrm{CN}\right)$ before recording a spectrum. The bands of adsorbed acetonitrile in the area $2360-2170 \mathrm{~cm}^{-1}$ are deconvoluted and fitted by Gaussian/Lorentzian profiles using OMNIC 8.3.103 software based on previously reported interactions. Quantitative results are obtained using molar absorption coefficients from the literature[28]: protonated $\mathrm{CD}_{3} \mathrm{CN}$ on Brønsted acid

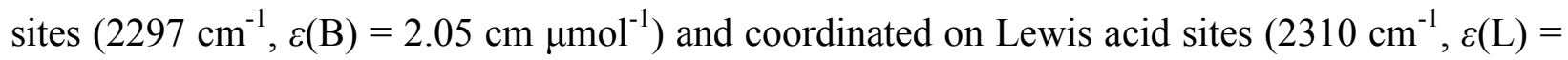
$3.60 \mathrm{~cm} \mu \mathrm{mol}^{-1}$ ). Both integrated areas of deconvoluted bands are normalized to a wafer mass of $20 \mathrm{mg}$. The Accessibility Index (ACI) is defined as the number of acid sites detected by a probe molecule divided by the total number of acid sites derived from the aluminum content. Accordingly, the pyridine $\mathrm{ACI}$, is $\mathrm{ACI}_{\mathrm{Py}}=\left(c_{\mathrm{B}}+c_{\mathrm{L}}\right) / \mathrm{Al}_{\mathrm{ICP}}$, as pyridine probes both Brønsted and Lewis acid sites, analogous for $d_{3}$-acetonitrile.

\section{Results}

The XRD patterns of all three zeolites after chromic acid treatment are almost identical to their respective parents (Figure 2A-C). All CHA (Figure 2A) treated with chromic acid solutions $(0.1-2 w / \%)$ are highly crystalline, up to $98 \% \mathrm{RC}$ (relative crystallinity). A moderate loss of crystallinity $(89 \%$ RC) occurs after treatment with $10 w / \%$ solution. All MFI treated with chromic acid are also highly crystalline (Figure 2B), with relative crystallinity up to $99 \%$ when dealuminated with $0.1-1 w / \%$ solutions. A minor decrease of crystallinity (97\%) in MFI-2 and MFI-10 is observed. All LTL zeolites treated with $0.1-1 w / \%$ acid solutions are highly crystalline, Figure 2C. A small loss of crystallinity is observed with a $2 w / \%$ solution, while with a $10 \quad w / \%$ solution, the resulting material is amorphous. 
A

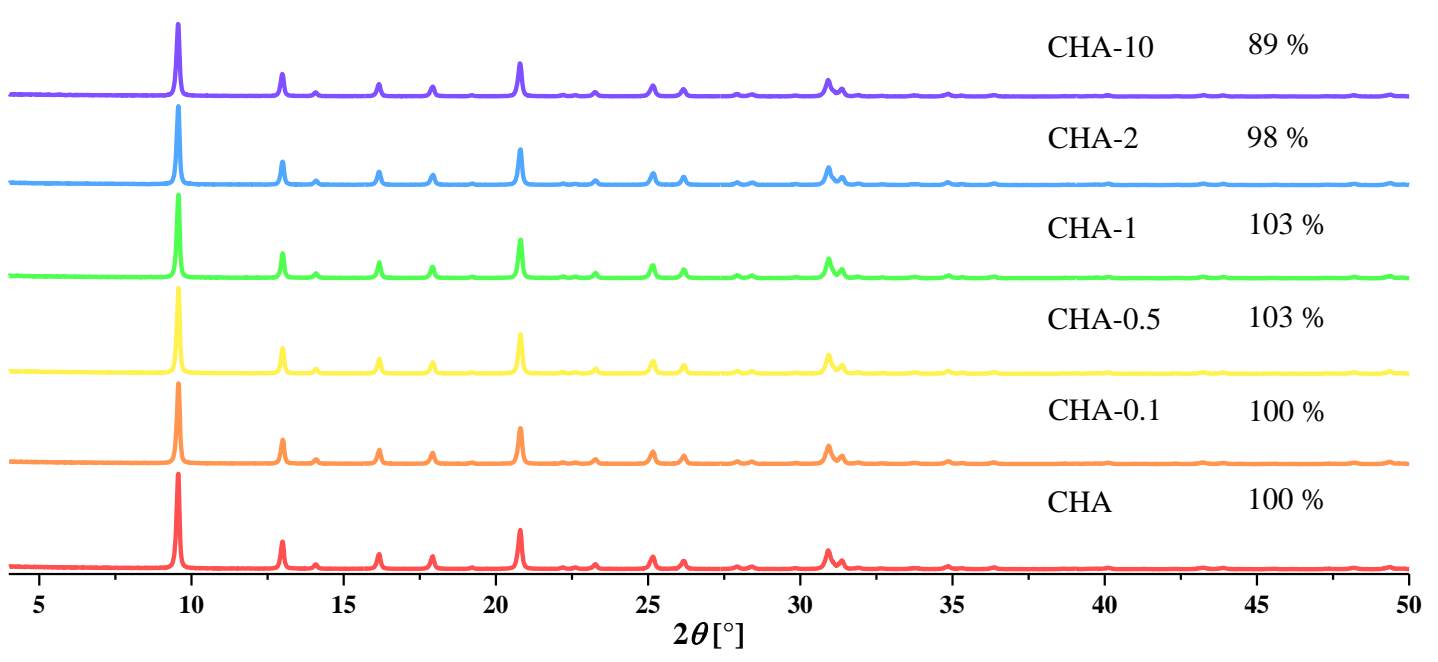

B

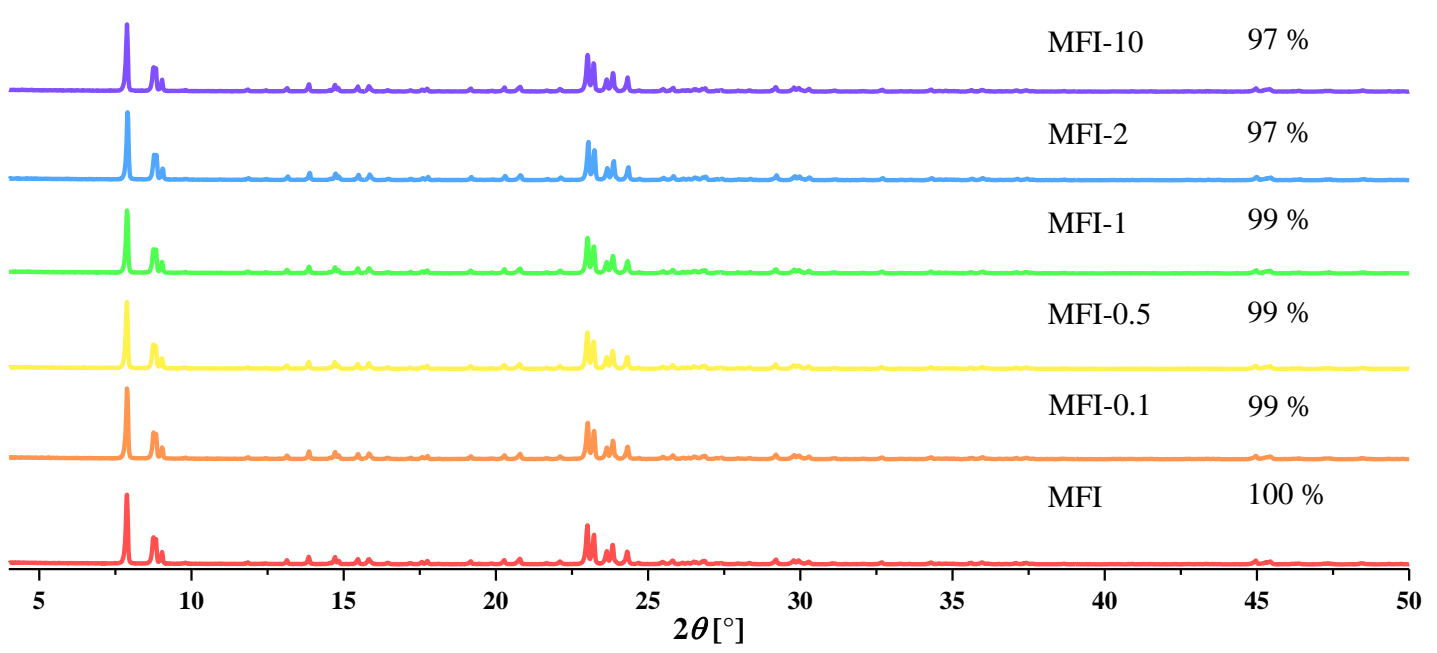

C

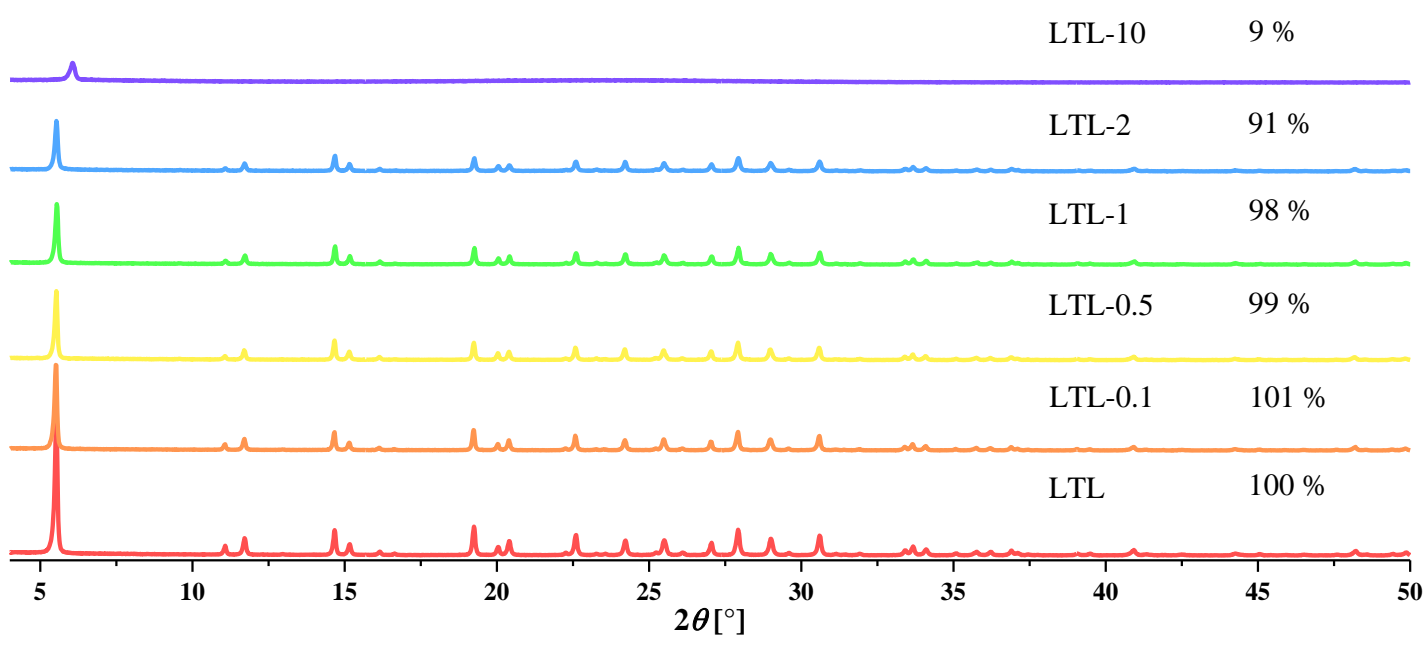


Figure 2. X-ray diffraction patterns of the parent and etched A) CHA, B) MFI, and C) LTL zeolites, with their corresponding relative crystallinity.

The impact of chromic acid on the zeolite morphology is studied with a scanning electron microscope with representative micrographs in Figure 3A-F. SSZ-13 crystals have the typical cubic appearance, with 100 and $500 \mathrm{~nm}$ crystallites, agglomerated in $1000 \mathrm{~nm}$ particles. CHA-1 (Figure 3A) and CHA-2 (Figure 3B) show the typical SSZ-13 cubic crystals' pristine surfaces with well-defined edges. The crystals appear intact after treatment with 1 and $2 w / \% \mathrm{CrO}_{3}$.

MFI crystals (Figure 3C-D) are $5 \mu \mathrm{m}$ long and $2 \mu \mathrm{m}$ wide and display a coffin-shaped morphology with intergrown crystals, ramps, and defects on the crystal surface.[29] The SEM micrographs show that large parts of the crystals are removed as it is likely some intergrown crystals are separated during etching. However, almost no traces of dissolution are observed on the crystal faces.

Zeolite L exhibits a disc-like morphology with overgrown terraces on its pinacoidal face (Figure 3E-F).[30] LTL-1 and LTL-2 show well-defined edges, and the crystal faces do not show visible traces of chromic acid treatment. SEM micrographs of untreated zeolites can be seen in Figure S2. 

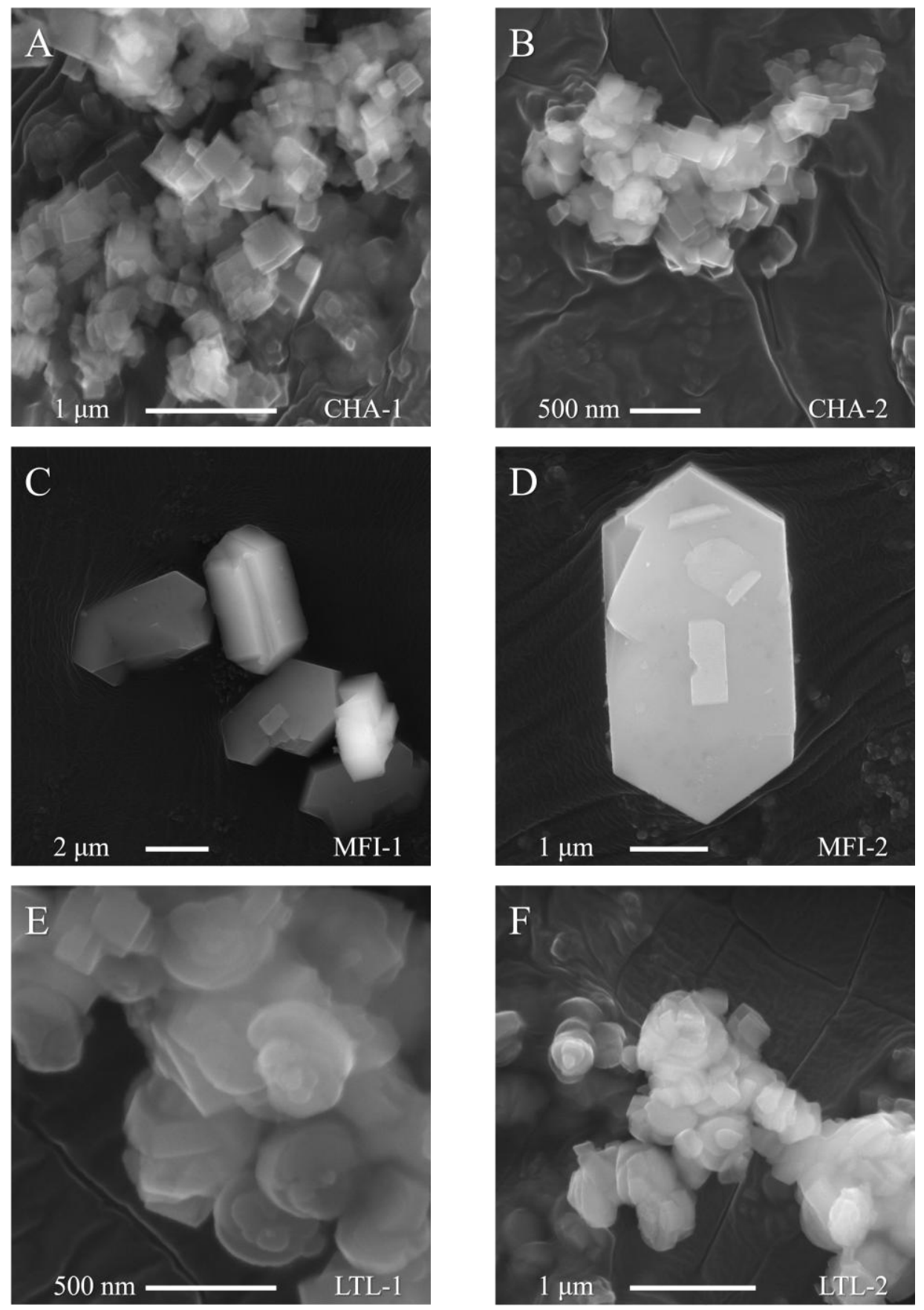

Figure 3. SEM micrographs of CHA (A, B), MFI (C, D) and LTL (E, F) etched zeolites.

Transmission electron microscopy brings more details on morphology. CHA-1 and CHA-2 retain their parent morphology, and no surface dissolution is observed (Figure 4A-B). 

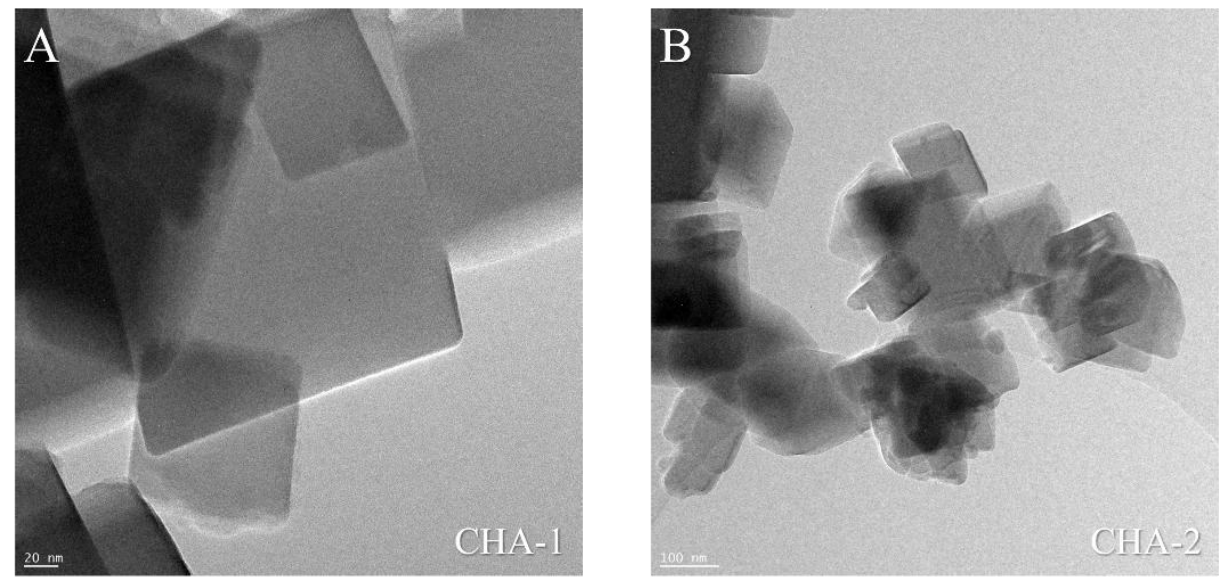

Figure 4. TEM micrographs of CHA-1 (A) and CHA-2 (B) zeolites.

LTL-0.1-30 exhibits the typical zeolite L morphology. However, on the crystal surface, small 10-20 nm holes penetrating the crystal core are observed (Figure 5A). At higher magnification (Figure 5B), a $15 \mathrm{~nm}$ pore starting from the crystal's external surface and penetrating $50 \mathrm{~nm}$ in the volume is visible.
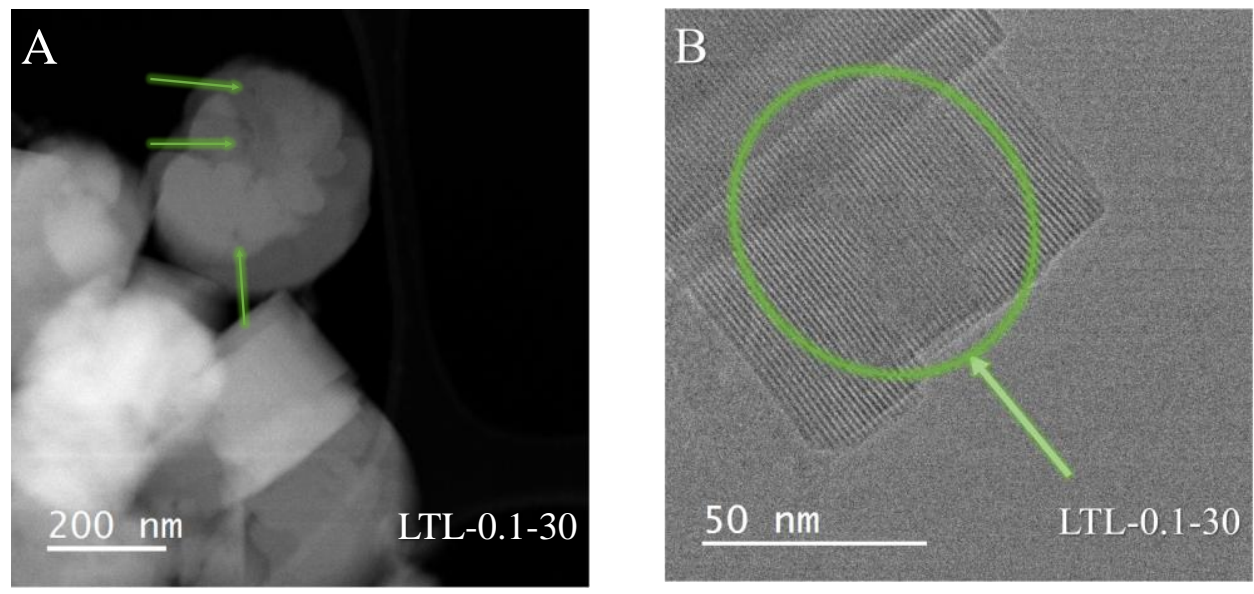

Figure 5. STEM micrographs of LTL-0.1-30 obtained by HAADF (left) and BF (right) imaging.

The parent zeolite $\mathrm{L}$ exhibit a $\mathrm{Si} / \mathrm{Al}$ ratio of 3 , as substantial variations of the framework composition are not observed in low silica zeolites. Chemical analysis by EDX is summarized in Figure S1. LTL-0.1-30 appears well washed since only small amounts of $\mathrm{Cr}(<0.4 w / \%)$ are 
detected. The $\mathrm{Si} / \mathrm{Al}$ ratio of 13, detected by EDX, indicates that the zeolite exhibits a gradient of $\mathrm{Al}$ distribution, where the surface is more depleted of $\mathrm{Al}$ due to the chromic acid treatment.

Nitrogen isotherms are gathered in Figure 6A-C. All parents (de-ammoniated CHA, MFI, and LTL), exhibit an I (a) type isotherm with an H4 hysteresis loop. Type I (a) isotherm is characteristic of microporous materials with a high uptake at low relative pressures $\left(p / p_{0}\right)$, while the H4 hysteresis loop indicates the presence of slit-shape pores. The quantitative results are summarized in Table 1.

The general features of the CHA derivatives isotherms are identical to their parent (Figure 6A), however, they exhibit a significant increase in micropore volume and no mesoporosity change. The increased micropore volume could be attributed to the removal of dense low pore volume contaminant. But since SEM/TEM does not reveal the presence of a non-zeolitic phase, the increase in micropore volume could originate from species obstructing access to the zeolite porosity; a chromic acid treatment appears to remove such entities

The etched MFI samples (Figure 6B) exhibit isotherms similar to their parent, with MFI-0.5 and MFI-1 showing a small increase in micropore volume, whereas MFI-2 and MFI-10 lose some.

All etched LTL (Figure 6C) lose some micropore volume, especially LTL-10, and develop some mesoporosity. The physisorption data and chemical analysis are summarized in Table $\mathbf{1}$. The three framework types showed different susceptibility to the chromic acid treatment.

The parent CHA zeolite has a micropore volume of $0.27 \mathrm{~cm}^{3} \mathrm{~g}^{-1}$ and mesopore volume of 0.04 $\mathrm{cm}^{3} \mathrm{~g}^{-1}$. The etched derivatives have an increased $V_{\text {micro }}$ but a constant $V_{\text {meso }}$. Their $V_{\text {micro }}$ increases to $0.29 \mathrm{~cm}^{3} \mathrm{~g}^{-1}$ after a $0.1 \mathrm{w} / \%$ etching (CHA-0.1) and up to $0.32 \mathrm{~cm}^{3} \mathrm{~g}^{-1}$ after $10 w / \%$ 
(CHA-10). Mesopore volume in all the treated samples is $0.04 \mathrm{~cm}^{3} \mathrm{~g}^{-1}$, and the external surface $\left(S_{B E T}\right)$ increases only slightly. The etched CHA samples also exhibit slight chemical composition changes. CHA-1 Si/Al ratio increases to 9.4 from 9.0 (CHA) and further to 10.5 (CHA-10) under more severe treatment. Such changes are not spectacular even though a highly aggressive acid solution is employed.
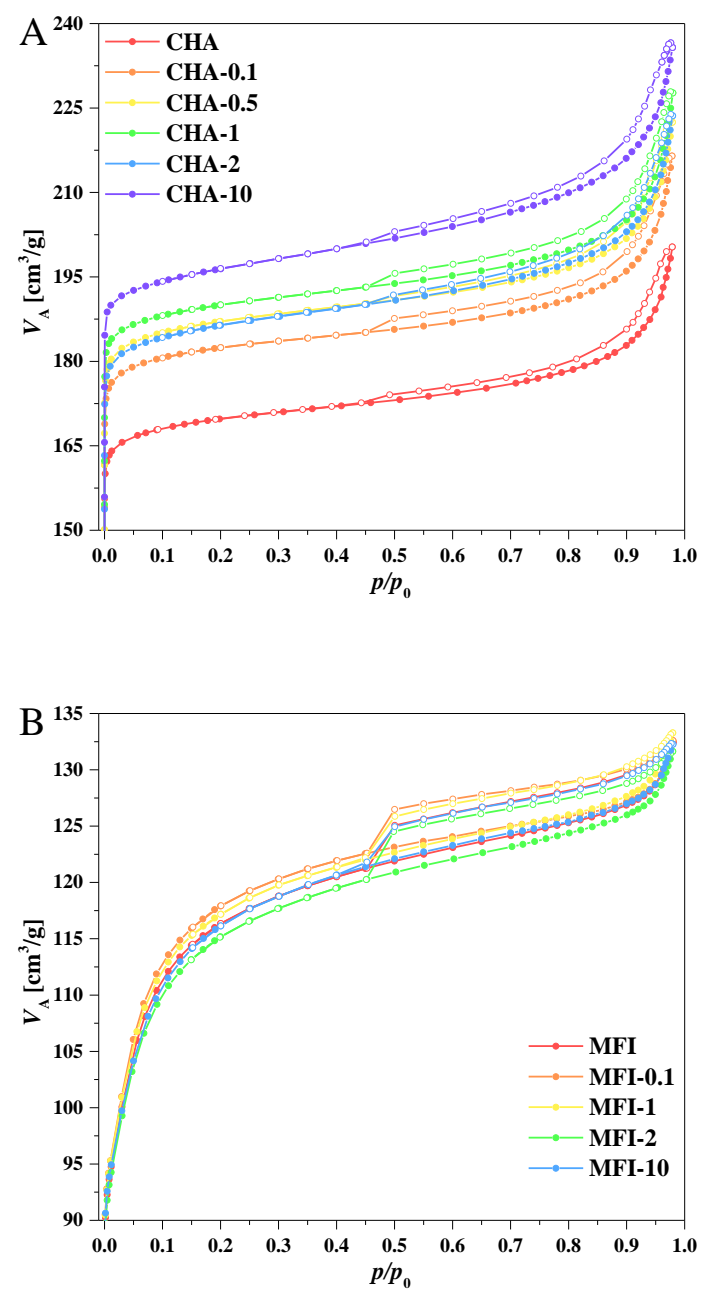


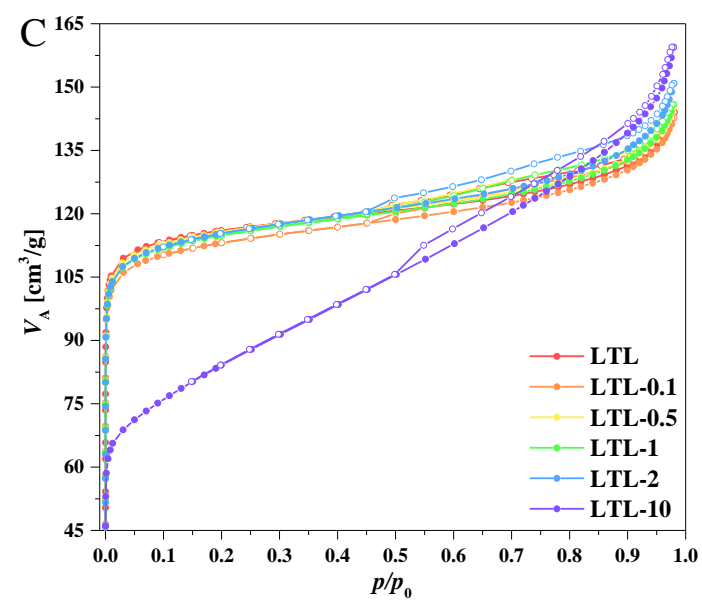

Figure 6. $\mathrm{N}_{2}$ isotherms of A) CHA, B) MFI, and C) LTL with their etched derivatives. Note: $\mathrm{y}$ axis has been offset to $45 \mathrm{~cm}^{3} \mathrm{~g}^{-1} / V_{\mathrm{A}}$ to better highlight microporosity changes.

The parent MFI has a micropore volume of $0.16 \mathrm{~cm}^{3} \mathrm{~g}^{-1}$, and its mesopore volume is $0.04 \mathrm{~cm}^{3} \mathrm{~g}^{-1}$. The etched MFI samples retain the same micropore and mesopore volumes, specific surface area $\left(S_{B E T}\right)$ whatever the acid solution concentration $(0.1-10 w / \%)$. However, the $\mathrm{Si} / \mathrm{Al}$ ratio of the etched MFI samples increases slightly, from 19 in the parent to 21, upon chromic acid etching.

The parent LTL has a micropore volume of $0.17 \mathrm{~cm}^{3} \mathrm{~g}^{-1}$, and its mesopore volume is $0.05 \mathrm{~cm}^{3} \mathrm{~g}^{-}$ 1. No changes occur after etching with 0.1 and $0.5 w / \%$ acid solutions, while with $1-4 w / \%$ micropore volume decreases slightly to $0.16 \mathrm{~cm}^{3} \mathrm{~g}^{-1}$. With a $10 \mathrm{w} / \%$ etching solution, a significant loss of micropore volume takes place, down to $0.09 \mathrm{~cm}^{3} \mathrm{~g}^{-1}$. While LTL-0.1-30 retains its parent $\mathrm{Si} / \mathrm{Al}$ ratio of 3.0 , it increases to 3.2 using $0.1-2 w / \%$ acids and to 6.1 with a 4 $w / \%$ acid.

Table 1. Physicochemical properties of the parent and treated zeolites.

\begin{tabular}{lllllll}
\hline Sample & $V_{\text {micro }}$ & $V_{\text {meso }}$ & $S_{\text {BET }}$ & $\mathrm{Si} / \mathrm{Al}_{\text {bulk }}$ & $\mathrm{Al}^{\mathrm{VI}}$ & $\mathrm{Si} / \mathrm{Al}^{\mathrm{IV}}$ \\
& $\mathrm{cm}^{3} \mathrm{~g}^{-1}$ & $\mathrm{~cm}^{3} \mathrm{~g}^{-1}$ & $\mathrm{~m}^{2} \mathrm{~g}^{-1}$ & $\mathrm{~mol} \mathrm{~mol}^{-1}$ & $\% \%^{*}$ & $\mathrm{~mol} \mathrm{~mol}^{-1}$ \\
\hline
\end{tabular}




\begin{tabular}{lllllll}
\hline CHA & 0.27 & 0.04 & 700 & 9.0 & 10.7 & 10.1 \\
CHA-0.1 & 0.29 & 0.04 & 735 & 9.4 & $/$ & $/$ \\
CHA-0.5 & 0.31 & 0.04 & 752 & 9.8 & 12.0 & 11.1 \\
CHA-1 & 0.32 & 0.04 & 765 & 9.9 & 12.5 & 11.3 \\
CHA-2 & 0.31 & 0.04 & 747 & 10.4 & 13.3 & 12.0 \\
CHA-10 & 0.32 & 0.04 & 788 & 10.5 & 14.0 & 12.2 \\
\hline MFI & 0.16 & 0.04 & 436 & 19 & 1.1 & 19.2 \\
MFI-0.1 & 0.16 & 0.04 & 440 & 21 & 1.6 & 21.3 \\
MFI-1 & 0.16 & 0.05 & 439 & 21 & 2.0 & 21.4 \\
MFI-2 & 0.16 & 0.04 & 430 & $/$ & 2.2 & $/$ \\
MFI-10 & 0.16 & 0.04 & 432 & 21 & 2.3 & 21.5 \\
\hline LTL & 0.17 & 0.05 & 456 & 3.0 & 0.1 & 3.0 \\
LTL-0.1-30 & 0.17 & 0.04 & 455 & 3.0 & 0.8 & 3.0 \\
LTL-0.1 & 0.17 & 0.05 & 450 & 3.1 & 1.0 & 3.1 \\
LTL-0.5 & 0.17 & 0.05 & 454 & $/$ & 4.5 & $/$ \\
LTL-1 & 0.16 & 0.05 & 426 & 3.2 & 4.9 & 3.4 \\
LTL-2 & 0.16 & 0.05 & 432 & 3.4 & 5.2 & 3.6 \\
LTL-4 & 0.16 & 0.05 & 417 & 6.1 & $/$ & $/$ \\
LTL-10 & 0.09 & 0.16 & 295 & $/$ & $/$ & $/$ \\
\hline Content & $0 x+5 a r a w 5$ & & \\
\hline
\end{tabular}

"Content of extraframework aluminum $\left(\mathrm{Al}^{\mathrm{V}}\right)$ expressed in percentages (\%), attained from ${ }^{27} \mathrm{Al}$ MAS NMR spectra.

${ }^{27}$ Al MAS NMR spectroscopy monitors the Al coordination after chromic acid etching.

The parent CHA, CHA (Figure 7A) exhibits three peaks related to octa-, penta- and tetrahedrally-coordinated aluminum. All etched derivatives show the same peaks with a small increase of intensity of octa-coordinated aluminum. The amount of octa-coordinated $\mathrm{Al}$ in the 
parent CHA is $10.7 \%$ (Table 1), while the derivatives contain slightly more, with a maximum of $14 \%$ in CHA- 10 .

The parent MFI (Figure 7B) exhibits a single peak at $\sim 60 \mathrm{ppm}$ associated with tetra-coordinated aluminum. The amount of visible hexa-coordinated is $c a .1 .0 \%$ (Table 1) and very similar on all etched derivatives (1.6 and $2.3 \%)$.

The parent LTL (Figure 7C) exhibits only a single peak at $\sim 60 \mathrm{ppm}$ associated to tetracoordinated Al. The derivatives etched with chromic acid concentrations in the $0.1-2 w / \%$ range show the presence of hexa-coordinated aluminum. The corresponding $\mathrm{Al}^{\mathrm{VI}}$ content is $0.8-5.2 \%$ (Table 1). A $10 w / \%$ etching solution has a significant effect as all peaks almost disappear due to an almost complete loss of crystallinity (Figure 2C).
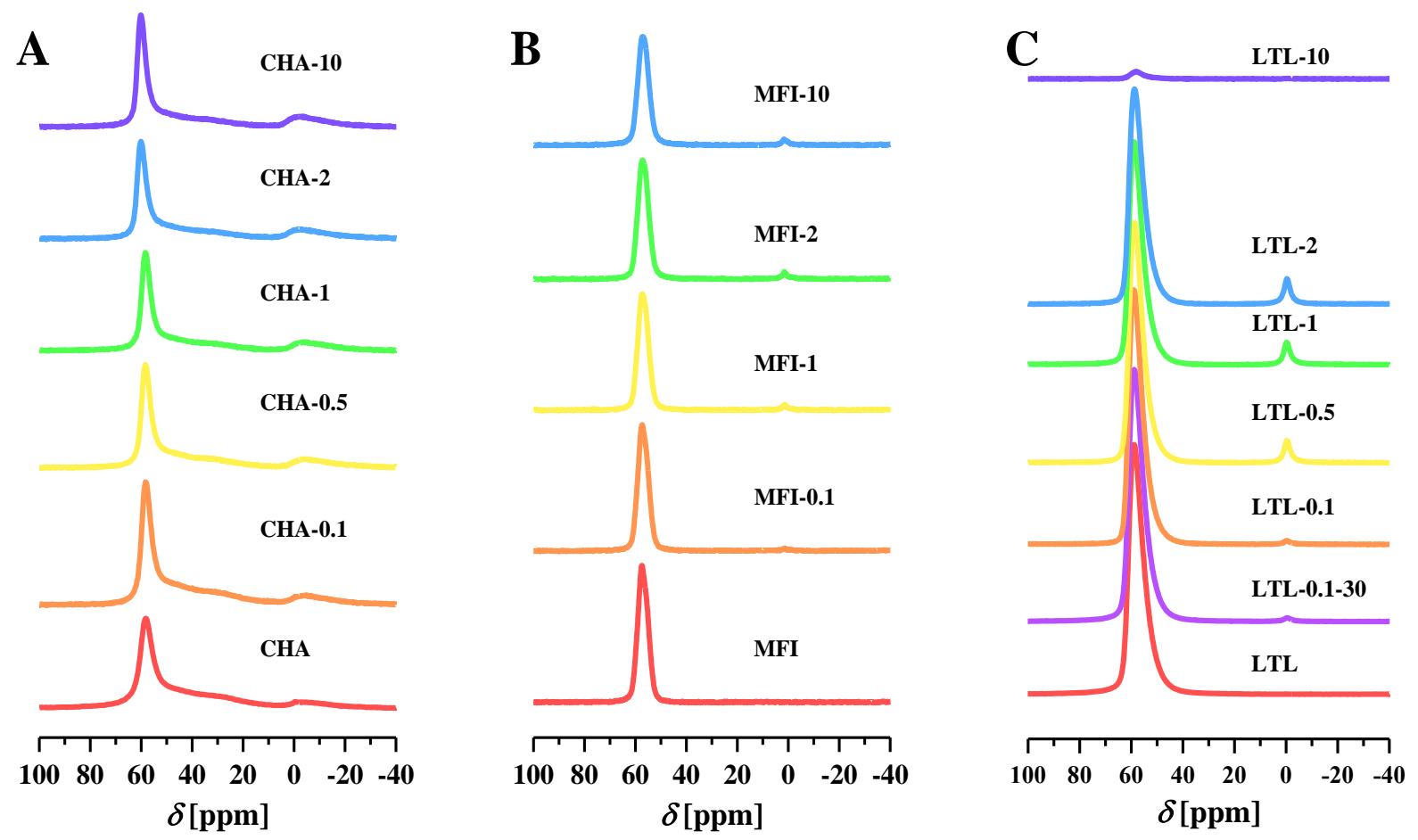

Figure 7. ${ }^{27} \mathrm{Al}$ MAS NMR spectra of A) CHA, B) MFI, and C) LTL series of samples. 
${ }^{29} \mathrm{Si}$ MAS NMR of all CHA zeolites comprises three peaks at chemical shifts $(\delta)-109,-103$, and -98 ppm, corresponding to $\mathrm{Si}(4 \mathrm{Si}, 0 \mathrm{Al}), \mathrm{Si}(3 \mathrm{Si}, 1 \mathrm{Al}), \mathrm{Si}(2 \mathrm{Si}, 2 \mathrm{Al})$, depicted in Figure $\mathbf{S 3 A}$. CHA-1 has lower intensities of all three peaks compared to its parent. ${ }^{29} \mathrm{Si}\left\{{ }^{1} \mathrm{H}\right\}$ crosspolarization NMR (Figure S3B) shows on the parent (CHA) broad peaks between -110 and -90 ppm and on the CHA-1 an increase in the -109 ppm peak intensity. The latter is related to silanols generated during etching with a $1 w / \% \mathrm{CrO}_{3}$ solution.

On the ${ }^{29}$ Si MAS NMR spectra of the parent LTL zeolite and its LTL-1 derivative, four peaks at chemical shifts $(\delta)-110,-106,-100$, and $-95 \mathrm{ppm}$ correspond to $\mathrm{Si}(4 \mathrm{Si}, 0 \mathrm{Al}), \mathrm{Si}(3 \mathrm{Si}, 1 \mathrm{Al})$, $\mathrm{Si}(2 \mathrm{Si}, 2 \mathrm{Al})$ and $\mathrm{Si}(1 \mathrm{Si}, 3 \mathrm{Al})$, respectively.[31] Figure 8A. The intensities of the peaks corresponding to $\mathrm{Si}(4 \mathrm{Si}, 0 \mathrm{Al}), \mathrm{Si}(3 \mathrm{Si}, 1 \mathrm{Al})$ increase relative to their parent, indicating dealumination.

The ${ }^{29} \mathrm{Si}\left\{{ }^{1} \mathrm{H}\right\}$ cross-polarization NMR spectra of LTL and LTL-1 (Figure 8B) display peaks at $110,-106,-100$, and $-96 \mathrm{ppm}$, corresponding to those in ${ }^{29} \mathrm{Si}$ MAS NMR, indicating that Si-O-Al and $\mathrm{Si}-\mathrm{O}-\mathrm{OH}$ peaks overlap in the latter. On LTL-1, the intensity of the -96 peak $(\mathrm{Si}(1 \mathrm{Si}, 3 \mathrm{OH}))$ decreases while those of the $\mathrm{Si}(2 \mathrm{Si}, 2 \mathrm{OH})$ at $-100 \mathrm{ppm}$ and $\mathrm{Si}(3 \mathrm{Si}, 1 \mathrm{OH})$ at $-105 \mathrm{ppm}$ increase slightly. A $1 w / \%$ chromic acid etching does not contribute significantly to the formation of silanol groups but somewhat to geminal and single silanols. 

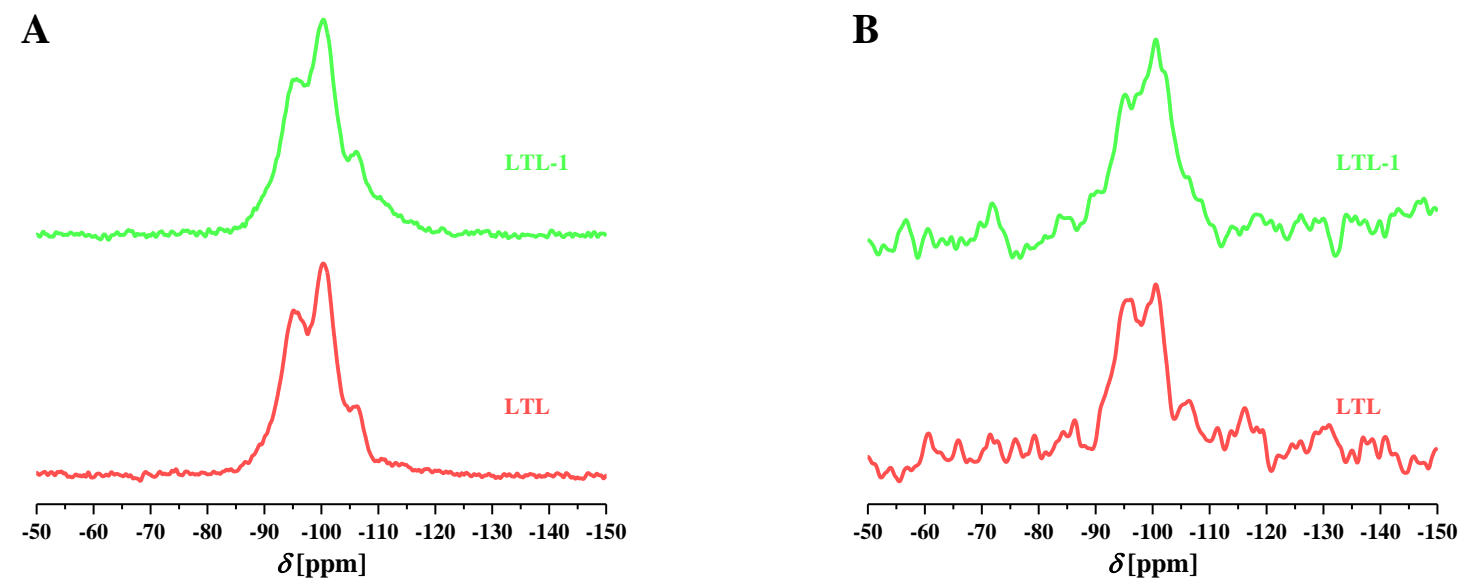

Figure 8. ${ }^{29}$ Si MAS NMR spectra of the parent LTL and its LTL-1 derivative (A) and their ${ }^{29} \mathrm{Si}\left\{{ }^{1} \mathrm{H}\right\}$ cross-polarization spectra (B).

The acidity of all CHA samples is measured by monitoring the adsorption of deuterated acetonitrile by IR spectroscopy. The room temperature spectra of the activated $\left(\mathrm{T}=450{ }^{\circ} \mathrm{C}\right)$ CHA and its etched derivatives are shown in Figure 9A. In the $\mathrm{OH}$ region $\left(3750-3450 \mathrm{~cm}^{-1}\right)$, seen in Figure S5, the bands at 3644, 3616, 3575 and $3538 \mathrm{~cm}^{-1}$ are attributed to the acidic $\mathrm{OH}$ groups corresponding to the four nonequivalent oxygens in the CHA structure.[31,32] A zoom on the $\mathrm{OH}$ region clearly distinguishes the four bridged hydroxyls, vide supra, from the external $\left(3742 \mathrm{~cm}^{-1}\right)$ and internal $\left(3735 \mathrm{~cm}^{-1}\right)$ isolated silanols; the deconvoluted spectra of the parent sample are in Figure S4. Figure S5 highlights that all samples are quite similar in the $\mathrm{OH}$ region. The band at $3716 \mathrm{~cm}^{-1}$ is assigned to vicinal silanol groups.[33] Brønsted acid sites are observed as a composite band centered around $3612 \mathrm{~cm}^{-1}$ with its shoulder at $3594 \mathrm{~cm}^{-1}$. The bands from 3680 to $3660 \mathrm{~cm}^{-1}$ corresponds to extraframework and distorted framework aluminum.[33] Figure 9B gathers the IR spectra of $\mathrm{CD}_{3} \mathrm{CN}$ adsorbed on the CHA zeolites; the characteristic bands are in the $2400-2150 \mathrm{~cm}^{-1}$ window. The adsorption of $d_{3}$-acetonitrile results in complex bands in the region $2350-2200 \mathrm{~cm}^{-1}$, deconvoluted in five peaks presented in Table S1. Figure 9B shows that the spectrum of CHA-0.5 is similar to its parent and the peak 
corresponding to Brønsted sites is slightly more intense. More concentrated chromic acid used for the preparation of CHA-1 and CHA-2 increase the Lewis's acidity.
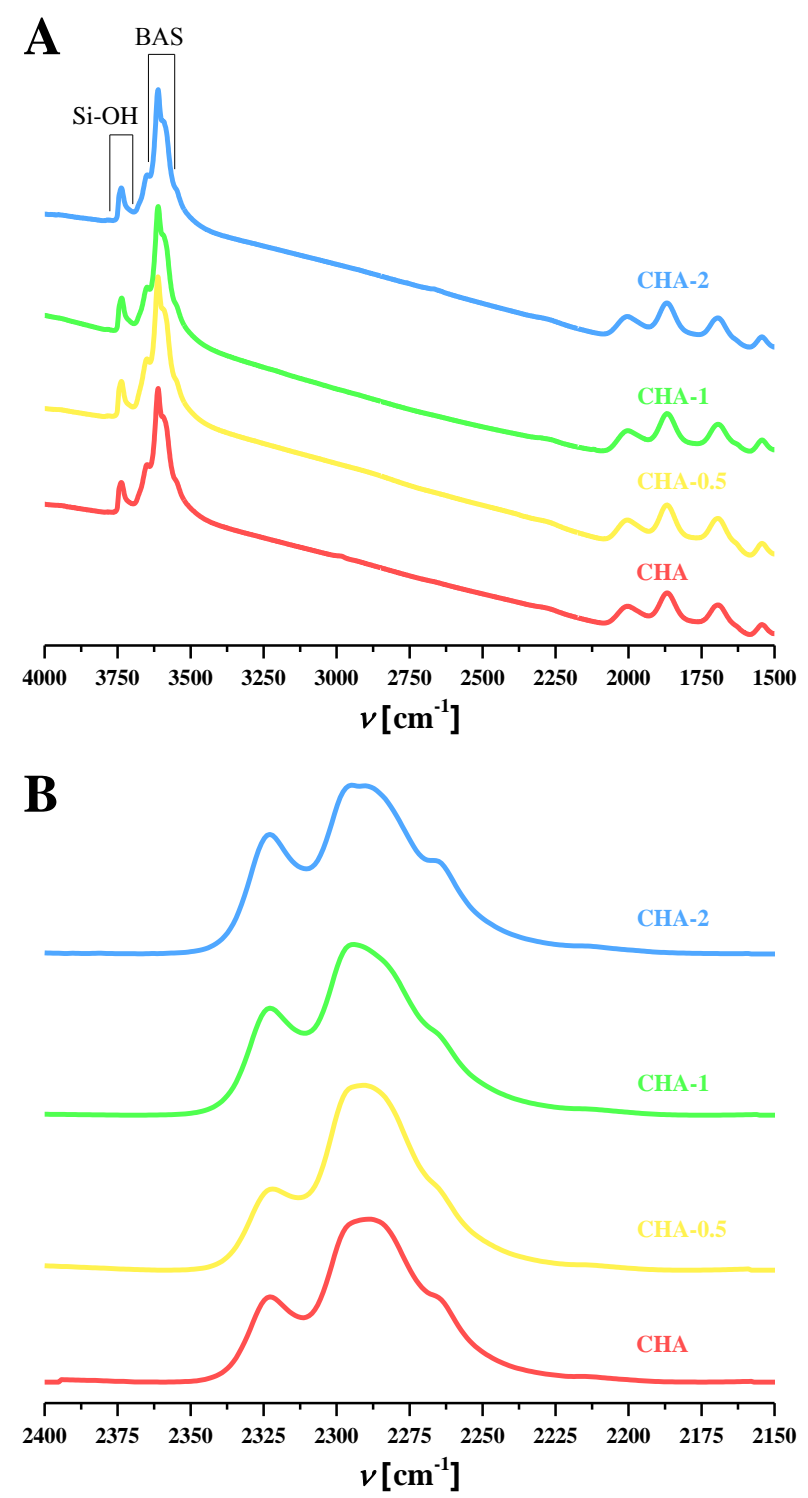

Figure 9. IR spectra of the CHA parent and its etched derivatives (A). IR spectra of adsorbed $d_{3^{-}}$ acetonitrile after saturation of the CHA acid sites (B).

The acid site concentrations and accessibilities are summarized in Table 2. The Brønsted sites accessibility increase for all etched samples. In the parent $\mathrm{CHA}, \mathrm{ACI}$ is 0.47 , while it raises to 
the $0.57-0.78$ range for the derivatives. CHA-1 has the highest BAS concentration ( $654 \mu \mathrm{mol} \mathrm{g}^{-}$ ${ }^{1}$ ), while the number of Lewis sites in CHA-1 and CHA-2 is 247 and $269 \mu \mathrm{mol} \mathrm{g}^{-1}$, respectively.

The in situ IR spectra in the hydroxyls range $\left(3700-3500 \mathrm{~cm}^{-1}\right)$ of the parent MFI shows two bands, $3744 \mathrm{~cm}^{-1}$ and $3610 \mathrm{~cm}^{-1}$ (Figure S6A), the $3744 \mathrm{~cm}^{-1}$ assigned to Si-OH, vibrating on the external crystal surface. The parent sample also exhibits a low-intensity peak at $3730 \mathrm{~cm}^{-1}$ assigned to Si-OH in defects.[26] The band at $3610 \mathrm{~cm}^{-1}$ belongs to the acidic bridging hydroxyls $\mathrm{Si}(\mathrm{OH}) \mathrm{Al}$. The treated samples MFI-0.5, MFI-1, and MFI-2 exhibit the same peaks; only MFI-2 shows a small intensity decrease of the $\mathrm{Si}(\mathrm{OH}) \mathrm{Al}$ band.

Pyridine adsorbed on acid sites is detected in the $1700-1400 \mathrm{~cm}^{-1}$ spectral window (Figure S6B). The band centered at $1545 \mathrm{~cm}^{-1}$ is related to protonated pyridine (Brønsted acidity), while the $1462 \mathrm{~cm}^{-1}$ is coordinated pyridine (Lewis acidity). IR spectra of pyridine remaining adsorbed after desorption at $200{ }^{\circ} \mathrm{C}$ are used to quantify the Brønsted and Lewis acid sites, and the results are presented in Table 2. The concentrations of Brønsted and Lewis acid sites increase with respect to the parent zeolite. MFI-1 exhibits the highest BAS concentration (431 $\left.\mu \mathrm{mol} \mathrm{g}{ }^{-1}\right)$, similar with MFI-0.5, while the concentration of BAS for MFI-2 is lower. The parent MFI has a

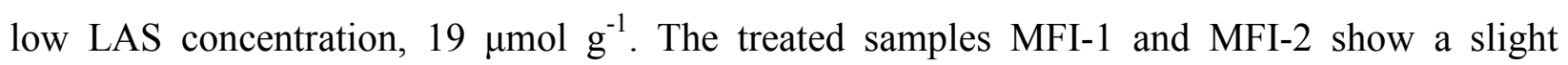
increase in LAS concentration, which reaches a maximum of $30 \mu \mathrm{mol} \mathrm{g}^{-1}$ in the case of MFI-2. The samples MFI-0.5 and MFI-1 show increased accessibility to the acid sites since higher concentrations of BAS and LAS are detected. However, the sample MFI-2 exhibits lower accessibility, and low concentrations of LAS and BAS are observed. 
Table 2. Acid site concentration ( $c_{b}$ : Bronsted, $c_{L}$ : Lewis) and accessibility by IR spectroscopy of probe molecules ( $d_{3}$-acetonitrile: CHA, pyridine: MFI and LTL) in the parent and etched zeolites.

\begin{tabular}{|c|c|c|c|c|c|}
\hline Sample & $\begin{array}{l}\mathrm{Al}_{\mathrm{ICP}} \\
\mu \mathrm{mol} \mathrm{g}^{-1}\end{array}$ & 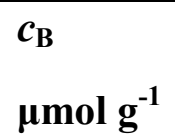 & $\begin{array}{l}c_{\mathrm{L}} \\
\mu_{\mathrm{mol} \mathrm{g}}{ }^{-1}\end{array}$ & $\begin{array}{l}c_{\mathrm{B}}+c_{\mathrm{L}} \\
\mu \mathrm{mol} \mathbf{g}^{-1}\end{array}$ & $\begin{array}{l}\mathrm{ACI} \\
-\end{array}$ \\
\hline H-CHA & 1234 & 401 & 176 & 578 & 0.47 \\
\hline CHA- 0.5 & 1141 & 503 & 158 & 661 & 0.57 \\
\hline CHA-1 & 1141 & 654 & 247 & 900 & 0.78 \\
\hline CHA-2 & 1080 & 447 & 269 & 716 & 0.66 \\
\hline Sample & $\begin{array}{l}\mathrm{Al}_{\mathrm{ICP}} \\
\mu \mathrm{mol} \mathrm{g}^{-1}\end{array}$ & 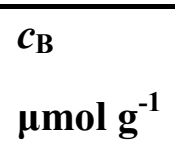 & 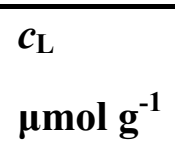 & $\begin{array}{c}c_{\mathrm{B}}+c_{\mathrm{L}}^{\mathrm{a}} \\
\mu \mathrm{mol} \mathrm{g} \mathbf{g}^{-1}\end{array}$ & $\begin{array}{l}\mathbf{A C I _ { P y }} \\
-\end{array}$ \\
\hline H-MFI & 612 & 418 & 19 & 437 & 0.71 \\
\hline MFI-0.5 & 556 & 418 & 23 & 441 & 0.79 \\
\hline MFI-1 & 556 & 431 & 30 & 461 & 0.83 \\
\hline MFI-2 & 556 & 362 & 30 & 392 & 0.71 \\
\hline Sample & $\begin{array}{l}\mathrm{Al}_{\mathrm{ICP}} \\
\mu_{\mathrm{mol} \mathrm{g}}{ }^{-1}\end{array}$ & 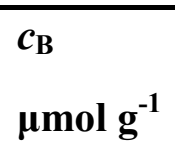 & $\begin{array}{l}c_{\mathrm{L}} \\
\mu \mathrm{mol} \mathrm{g}^{-1}\end{array}$ & $\begin{array}{l}c_{\mathrm{B}}+c_{\mathrm{L}}^{\mathrm{b}} \\
\mu \mathrm{mol} \mathrm{g}^{-1}\end{array}$ & $\begin{array}{l}\overline{A C I_{P y}} \\
-\end{array}$ \\
\hline H-LTL & 3156 & 412 & 233 & 645 & 0.20 \\
\hline LTL-0.5 & 3076 & 507 & 194 & 701 & 0.23 \\
\hline LTL-1 & 3000 & 469 & 245 & 714 & 0.24 \\
\hline LTL-2 & 2859 & 435 & 167 & 602 & 0.21 \\
\hline
\end{tabular}

${ }^{\mathrm{a}}$ Determined at $200{ }^{\circ} \mathrm{C},{ }^{\mathrm{b}} 150{ }^{\circ} \mathrm{C}$

The parent LTL and its chromic acid-treated derivatives acidic properties are studied by in situ infrared (IR) spectroscopy of their -OH stretching vibrations (Figure S7A). The peak observed at 
$3746 \mathrm{~cm}^{-1}$ is assigned to $\mathrm{Si}-\mathrm{OH}$, vibrating on the external crystal surface and the mesopore area. The samples also have a low-intensity peak at $3730 \mathrm{~cm}^{-1}$, commonly assigned to Si-OH in defects.[26] The peak at $3634 \mathrm{~cm}^{-1}$ is assigned to bridging hydroxyl $\mathrm{Si}(\mathrm{OH}) \mathrm{Al}$ groups and the broadband at $3250 \mathrm{~cm}^{-1}$ to the hydroxyls located in the cancrinite cage.[34,35] An increase of silanol band in respect to the parent is observed in samples LTL-1 and LTL-2.

IR spectra of pyridine remaining adsorbed after desorption at $150{ }^{\circ} \mathrm{C}$ (Figure S7B) are used to quantify the Brønsted and Lewis acid sites presented in Table 2. The concentrations of Brønsted and Lewis acid sites increase with respect to the parent zeolite. LTL-0.5, LTL-1, and LTL-2 show increased BAS concentration compared to their LTL parent. LAS concentration in LTL-0.5 and LTL-2 is lower than in the parent, despite the presence of extraframework Al, determined by ${ }^{27} \mathrm{Al}$ MAS NMR (Figure 7). The number of Lewis sites is higher in the LTL-1 sample, which we attribute to not optimally washed extraframework aluminum. Nevertheless, the LTL-1 shows the highest $\mathrm{ACI}_{\mathrm{Py}}$. The accessibility index $\left(\mathrm{ACI}_{\mathrm{Py}}\right)$ of all chromic acid-treated samples is higher than their parent. 


\section{Discussion}

The potential of chromic acid to treat a wide range of zeolites (SSZ-13, MFI-55, LTL) is studied as it has not yet been used previously to remove framework atoms. These commercially available zeolites have different framework topologies, pore and crystal sizes, $\mathrm{Si} / \mathrm{Al}$ ratios. We find that despite these differences one parameter that is often disregarded in acid dealumination is the acid anion and here we find it is the major cause in low reactivity of 8 and 10 MR zeolites. The $8 \mathrm{MR}$ (CHA) and $10 \mathrm{MR}$ (MFI) zeolites are more resistant to acid treatment with chromic acid than the 12 MR (LTL) zeolite.

Chromic acid is generally considered a very strong acid since for the first deprotonation reaction $p K_{\mathrm{A}}$ is found to be -0.7.[36] We expected such a strong acid to dissolve zeolites easily and cause amorphization, as it often happens with concentrated strong acids. However, the studied zeolites withstand such an attack and retain their crystallinity, shown by the XRD patterns in Figure 2. The MFI structure is the most resilient with the highest relative crystallinity values (RC $97 \%$ ) even after a $10 w / \%$ concentrated acid treatment. Under similar conditions, SSZ-13 (CHA-10) has a relative crystallinity of $89 \%$, while LTL-10 is mostly amorphous. Other LTL derivatives $(0.1-1 w / \%$ chromic acid concentration) retain a high (91-101\%) relative crystallinity.

The morphology and surface characteristics, as revealed by SEM, TEM and $\mathrm{N}_{2}$ physisorption, follow well the data obtained with XRD. For instance, the $\mathrm{N}_{2}$ physisorption on CHA shows that micropore volume in treated samples significantly increases, from $0.27(\mathrm{CHA})$ to $0.32 \mathrm{~cm}^{3} \mathrm{~g}^{-1}$ (CHA-10). Meyers et al. concluded that $60 \%$ of micropore volume in commercial mordenite was covered with pore-blocking, non-framework material, which can be removed by acid treatment.[37] This is reflected in the higher accessibility of $d_{3}$-acetonitrile in the spectroscopic 
study. The increase in the micropore volume is not accompanied by any changes in the mesopore volume. On the other side, the external surface area $\left(S_{B E T}\right)$ slightly increases, in agreement with SEM and TEM, showing no traces of surface dissolution. Chromic acid potentially removes dense phases from the crystal surface, which blocks part of zeolite pores, leading to the increase of the micropore volume in most cases.

MFI crystals do not show any signs of surface etching, similarly to CHA crystals, but a separation of intergrown crystals is observed. It is worth noting that MFI crystals are much larger than those of SSZ-13 and LTL, which has an impact on the diffusion of the etching solution. Only a small increase in the micropore volume is detected in the $\mathrm{N}_{2}$ isotherms of MFI- 0.1 and MFI-1. Although some signs of surface dissolution was observed in the etched LTL samples, their mesoporosity remains unchanged (Table 1). The sample treated with $10 w / \%$ shows a significant loss of the micropore volume, almost half of the initial value $\left(0.17 \mathrm{~cm}^{3} \mathrm{~g}^{-1)}\right.$, having $V_{\text {micro }}=0.09 \mathrm{~cm}^{3} \mathrm{~g}^{-1}$. The LTL treated with 0.1 and $0.5 w / \%$ acid solutions retain the micropore volume. While samples treated with $1-4 w / \%$ chromic acid show a small decrease of the micropore volume, having $0.16 \mathrm{~cm}^{3} \mathrm{~g}^{-1} V_{\text {micro }}$.

The chromic acid treatment causes some increase in the $\mathrm{Si} / \mathrm{Al}$ ratio for all zeolite treated, though in most cases, like CHA and MFI, it is far from a substantial increase in the $\mathrm{Si} / \mathrm{Al}$ ratio. Hence, it is more likely some Al-rich dense amorphous phases get removed which leads to an overall increase in the $\mathrm{Si} / \mathrm{Al}$ ratio. $\mathrm{CHA}-10$ has a $\mathrm{Si} / \mathrm{Al}$ ratio of 10.5 , against 9.0 for its parent. MFI, with particle size around $5 \mu \mathrm{m}$ and a $\mathrm{Si} / \mathrm{Al}=19$, are not much affected by the chromic acid treatment. Some aluminum-rich defect zones are likely removed, and intergrown crystals separated during the chromic acid treatment, leading to only a slight $\mathrm{Si} / \mathrm{Al}$ ratio increase. The LTLs treated with solutions $0.1-2 w / \%$ retain $\mathrm{Si} / \mathrm{Al}$ ratio in the 3.0-3.4 range, very close to their parent (3.0). Only 
LTL-4 increases its Si/Al ratio to 6.1, as the dealumination is clearly highlighted by ${ }^{27} \mathrm{Al}$ MAS NMR (Figure 7C). LTL-10 shows a significant intensity loss of tetrahedral aluminum, indicating an amorphization likely due to a combination of its low $\mathrm{Si} / \mathrm{Al}$ ratio and large pores. LTL treated under milder conditions (concentrations $0.1-2 w / \%$ ) show the formation of extraframework aluminum. The same effect is observed with CHA and MFI samples; however, LTL has the highest increase of $\mathrm{Al}^{\mathrm{VI}}$, which for sample LTL-2 is $5.2 \%$. CHA and MFI treated samples have an $\mathrm{Al}^{\mathrm{VI}}$ increase of up to 3.3 and $2.3 \%$, respectively, even for the most concentrated acid solutions. Guyot et al. previously concluded that chromic acid breaks aluminoxane bonds in amorphous silica-aluminas, and aluminum forms soluble complexes with chromic acid in a ratio 1:3.[38] Similar species could explain the increase of extraframework aluminum in treated zeolites and the significant decrease of LTL microporosity by pore blocking. The dealumination of zeolite frameworks typically leads to the formation of silanol defects, in a ratio of 4 to 1 . ${ }^{29} \mathrm{Si}\left\{{ }^{1} \mathrm{H}\right\}$ cross-polarization NMR spectra of LTL-1 doesn't show a significant increase of silanol defects compared to its parent (Figure 8B). In contrast, on CHA-1 the presence silanol defects (nests) is manifested. It is likely that the chrome anions are too large to enter the $8 \mathrm{MR}$ of the chabazite framework and thus react primarily on the external surface, which is why only the external surface is increased ( $S_{\mathrm{BET}}$, Table 1). The solutions we prepared to correspond to $\mathrm{pH}$ between 2 and 0 . Generally, the existence of $\mathrm{Cr}_{2} \mathrm{O}_{7}{ }^{2-}, \mathrm{HCrO}_{4}^{-}, \mathrm{H}_{2} \mathrm{CrO}_{4}, \mathrm{Cr}_{3} \mathrm{O}_{10}{ }^{2-}$ and $\mathrm{Cr}_{4} \mathrm{O}_{13}{ }^{2-}$ is contemplated and debated in this area. Only a chromate anion (naked $\mathrm{CrO}_{4}{ }^{2-}, 0.27 \mathrm{~nm}$ ) could enter the CHA pores, but this anion only forms in the basic environment. All the other species $\left(\mathrm{Cr}_{2} \mathrm{O}_{7}{ }^{2-}: 0.56 \mathrm{~nm}, \mathrm{H}_{2} \mathrm{CrO}_{4}: 0.46 \mathrm{~nm}\right.$ ) occurring under our $\mathrm{pH}$ conditions (ca. $\left.\sim 2\right)$ are too big to penetrate the CHA microporosity. This limitation also applies to MFI pores. We attribute the substantial dealumination of LTL crystals to be due to their large pore 12 MR pores which 
provide an aperture of $0.71 \mathrm{~nm}$ that is large enough to able the diffusion of $\mathrm{Cr}$ (VI) species. We presume that in the case of LTL the dealumination reaction doesn't just occur on the surface of the crystals, which is why in LTL-4 sample, $45 \%$ of total aluminum is removed from the sample. The chromic acid treatment results suggest the possibility of according the concentration and the size of anions in solution to adjust the treatment to the size of zeolite pores. Thus, the concentration of the chromic acid solution could be adjusted as a function of zeolite features.

As a result of surface concentrated dealumination, the BAS is preserved to a great extent in CHA. In MFI-0.5 and MFI-1, accessibility is increased as a result of the removal of structural defects in large crystals, while in LTL-0.5 and LTL-1, accessibility increases by the selective dissolution of low crystalline portions of the sample. 


\section{Conclusion}

Three commercially available zeolites (CHA, MFI, and LTL) are etched with chromic acid solutions with concentrations ranging between 0.1 and $10 \mathrm{w} / \%$. Such treatment does not introduce any substantial secondary porosity but causes some mild dealumination depending on the zeolite pore size and the concentration of the chromic acid solution. Chromic acid etching offers an opportunity to tune the population and the size of anions in solution to adjust the treatment to the size zeolite pores as observed in the 8 MR (CHA) and 10 MR (MFI). The acid treatment provokes a slight dealumination, preserving the total number of Brønsted acid sites but increasing their accessibility. $8 \mathrm{MR}$ and $10 \mathrm{MR}$ zeolites are more resistant to acid treatment with chromic acid than 12 MR zeolites, due to the size of the dichromate anions present in the solution.

In more general terms, this exploratory study with chromic acid solutions offers a new option to control zeolite dealumination by selecting and controlling the size of the etching anions. 
ASSOCIATED CONTENT

\section{Supporting Information.}

Contains EDX results, ${ }^{29} \mathrm{Si}$ MAS NMR of CHA samples, additional IR results of CHA, MFI and LTL samples (PDF).

\section{AUTHOR INFORMATION}

\section{Corresponding Author}

*Valentin Valtchev, valtchev@ensicaen.fr

\section{Author Contributions}

The manuscript was written through contributions of all authors. All authors have given approval to the final version of the manuscript.

\section{Funding Sources}

J.-P.G. and V.V. acknowledge the Industrial Chair ANR-TOTAL "NanoCleanEnergy" (ANR17-CHIN-0005-01) and FEDER 18P01675 contract for financial support. SK, SM and VV acknowledge the financial support of Carnot Institute (Energie et Systeme de Propulsion), the 3DNanoZET project. GENESIS is supported by the Région Haute-Normandie, the Métropole Rouen Normandie, the CNRS via LABEX EMC and the French National Research Agency as a part of the program "Investissements d'avenir" with the reference ANR-11-EQPX-0020.

\section{ACKNOWLEDGMENT}

V.B. acknowledges the $\mathrm{PhD}$ grant (RIN 100) from the Normandy region. 


\section{REFERENCES}

[1] R.M. Barrer, M.B. Makki, Molecular Sieve Sorbents from Clinoptilolite, Can. J. Chem. 42 (1964) 1481-1487. https://doi.org/10.1139/v64-223.

[2] H.G. Karge, H.K. Beyer, Solid-State Ion Exchange in Microporous and Mesoporous Materials, in: Post-Synthesis Modification I, Springer, Berlin, Heidelberg, 2002: pp. 43-201. https://doi.org/10.1007/3-540-69750-0_2.

[3] L. Zhang, A.N.C. van Laak, P.E. de Jongh, K.P. de Jong, Textural Characterization of Mesoporous Zeolites, in: J. Čejka, A. Corma, S. Zones (Eds.), Zeolites and Catalysis, WileyVCH Verlag GmbH \& Co. KGaA, Weinheim, Germany, 2010: pp. 237-282. https://doi.org/10.1002/9783527630295.ch9.

[4] M.J. Van Niekerk, J.C.Q. Fletcher, C. T. O’Connor, Characterization of dealuminated large-port mordenites, Journal of Catalysis. 138 (1992) 150-163. https://doi.org/10.1016/00219517(92)90014-9.

[5] E.B. Lami, F. Fajula, D. Anglerot, T. Des Courieres, Single step dealumination of zeolite beta precursors for the preparation of hydrophobic adsorbents, Microporous Materials. 1 (1993) 237-245. https://doi.org/10.1016/0927-6513(93)80067-5.

[6] B. Kraushaar, J.H.C. Van Hooff, A new method for the preparation of titanium-silicalite (TS-1), Catal Lett. 1 (1988) 81-84. https://doi.org/10.1007/BF00772769.

[7] V. Valtchev, G. Majano, S. Mintova, J. Pérez-Ramírez, Tailored crystalline microporous materials by post-synthesis modification, Chem. Soc. Rev. 42 (2012) 263-290. https://doi.org/10.1039/C2CS35196J.

[8] W. Vermeiren, J.-P. Gilson, Impact of Zeolites on the Petroleum and Petrochemical Industry, Top Catal. 52 (2009) 1131-1161. https://doi.org/10.1007/s11244-009-9271-8.

[9] C.-Y. Chen, S.I. Zones, Post-Synthetic Treatment and Modification of Zeolites, in: J. Čjka, A. Corma, S. Zones (Eds.), Zeolites and Catalysis, Wiley-VCH Verlag GmbH \& Co. KGaA, Weinheim, Germany, 2010: pp. 155-170. https://doi.org/10.1002/9783527630295.ch6.

[10] W. Khan, X. Jia, Z. Wu, J. Choi, A.C.K. Yip, Incorporating Hierarchy into Conventional Zeolites for Catalytic Biomass Conversions: A Review, Catalysts. 9 (2019) 127. https://doi.org/10.3390/cata19020127.

[11] F.A. Cotton, G.F.R.S. Wilkinson, Advanced Inorganic Chemistry, 3rd ed., InterScience Publishers, Toronto, 1972.

[12] R.K. Tandon, P.T. Crisp, J. Ellis, Effect of $\mathrm{pH}$ on chromium(VI) species in solution, Talanta. 31 (1984) 227-228. https://doi.org/10.1016/0039-9140(84)80059-4.

[13] C. Kasper, The structure of the chromic acid plating bath: The theory of chromium deposition, BUR. STAN. J. RES. 9 (1932) 353. https://doi.org/10.6028/jres.009.026. 
[14] C.E. Housecraft, A.G. Sharpe, Inorganic Chemistry, 3rd ed., Pearson Education Limited, Harlow, England, 2008.

[15] R. Šarmaitis, V. Dikinis, V. Rézaité, Equilibrium in Solutions of Chromic Acid, Plating and Surface Finishing. (1996) 53.

[16] A.F. Wells, Structural Inorganic Chemistry, 4th ed., Oxford University Press, London, 1975.

[17] J.S. Stephens, D.W.J. Cruickshank, The crystal structure of (CrO3) $\infty$, Acta Crystallographica Section B. 26 (1970) 222-226. https://doi.org/10.1107/S0567740870002182.

[18] F. Brito, J. Ascanio, S. Mateo, C. Hernández, L. Araujo, P. Gili, P. Martín-Zarza, S. Domínguez, A. Mederos, Equilibria of chromate(VI) species in acid medium and ab initio studies of these species, Polyhedron. 16 (1997) 3835-3846. https://doi.org/10.1016/S02775387(97)00128-9.

[19] J. Pecaut, R. Masse, Structure of bis(2-amino-5-nitropyridinium) dichromate as a step towards the design of efficient organic-inorganic non-linear optical crystals, Acta Crystallographica Section B. 49 (1993) 277-282. https://doi.org/10.1107/S0108768192008553.

[20] A. Stępień, M.J. Grabowski, Guanidinium trichromate, Acta Crystallographica Section B. 33 (1977) 2924-2927. https://doi.org/10.1107/S0567740877009832.

[21] J.D. Ramsey, L. Xia, M.W. Kendig, R.L. McCreery, Raman spectroscopic analysis of the speciation of dilute chromate solutions, Corrosion Science. 43 (2001) 1557-1572. https://doi.org/10.1016/S0010-938X(00)00145-1.

[22] P. Walker, W.H. Tarn, CRC Handbook of Metal Etchants, CRC Press, 1990.

[23] D.G. Schimmel, Defect Etch for $<100>$ Silicon Evaluation, J. Electrochem. Soc. 126 (1979) 479. https://doi.org/10.1149/1.2129066.

[24] T. Usui, Z. Liu, H. Igarashi, Y. Sasaki, Y. Shiramata, H. Yamada, K. Ohara, T. Kusamoto, T. Wakihara, Identifying the Factors Governing the Early-Stage Degradation of CuChabazite Zeolite for NH3-SCR, ACS Omega. 4 (2019) 3653-3659. https://doi.org/10.1021/acsomega.8b03409.

[25] D32 Committee, Test Method for Determination of Relative Crystallinity of Zeolite Sodium A by X-ray Diffraction, ASTM International, 2020. https://doi.org/10.1520/D5357-19.

[26] K.A. Tarach, J. Tekla, U. Filek, A. Szymocha, I. Tarach, K. Góra-Marek, Alkaline-acid treated zeolite L as catalyst in ethanol dehydration process, Microporous and Mesoporous Materials. 241 (2017) 132-144. https://doi.org/10.1016/j.micromeso.2016.12.035.

[27] C.A. Emeis, Determination of Integrated Molar Extinction Coefficients for Infrared Absorption Bands of Pyridine Adsorbed on Solid Acid Catalysts, Journal of Catalysis. 141 (1993) 347-354. https://doi.org/10.1006/jcat.1993.1145. 
[28] B. Wichterlová, Z. Tvarůžková, Z. Sobalík, P. Sarv, Determination and properties of acid sites in H-ferrierite: A comparison of ferrierite and MFI structures, Microporous and Mesoporous Materials. 24 (1998) 223-233. https://doi.org/10.1016/S1387-1811(98)00167-X.

[29] M.B.J. Roeffaers, R. Ameloot, M. Baruah, H. Uji-i, M. Bulut, G. De Cremer, U. Müller, P.A. Jacobs, J. Hofkens, B.F. Sels, D.E. De Vos, Morphology of Large ZSM-5 Crystals Unraveled by Fluorescence Microscopy, J. Am. Chem. Soc. 130 (2008) 5763-5772. https://doi.org/10.1021/ja7113147.

[30] O. Larlus, V.P. Valtchev, Crystal Morphology Control of LTL-Type Zeolite Crystals, Chem. Mater. 16 (2004) 3381-3389. https://doi.org/10.1021/cm0498741.

[31] G. Engelhardt, Multinuclear solid-state NMR in silicate and zeolite chemistry, TrAC Trends in Analytical Chemistry. 8 (1989) 343-347. https://doi.org/10.1016/01659936(89)87043-8.

[32] K. Suzuki, G. Sastre, N. Katada, M. Niwa, Ammonia IRMS-TPD measurements and DFT calculation on acidic hydroxyl groups in CHA-type zeolites, Phys. Chem. Chem. Phys. 9 (2007) 5980-5987. https://doi.org/10.1039/B711961E.

[33] S. Bordiga, L. Regli, D. Cocina, C. Lamberti, M. Bjørgen, K.P. Lillerud, Assessing the Acidity of High Silica Chabazite $\mathrm{H}-\mathrm{SSZ}-13$ by FTIR Using $\mathrm{CO}$ as Molecular Probe: Comparison with H-SAPO-34, J. Phys. Chem. B. 109 (2005) 2779-2784. https://doi.org/10.1021/jp045498w.

[34] E. Brunner, K. Beck, M. Koch, L. Heeribout, H.G. Karge, Verification and quantitative determination of a new type of Brønsted acid sites in H-ZSM-5 by $1 \mathrm{H}$ magic-angle spinning nuclear magnetic resonance spectroscopy, Microporous Materials. 3 (1995) 395-399. https://doi.org/10.1016/0927-6513(94)00052-W.

[35] H.G. Karge, E. Geidel, Vibrational Spectroscopy, in: H.G. Karge, J. Weitkamp (Eds.), Characterization I: -/-, Springer, Berlin, Heidelberg, 2004: pp. 1-200. https://doi.org/10.1007/b94235.

[36] G. Grampp, S. Landgraf, T. Wesierski, B. Jankowska, E. Kalisz, D.-M. Sabou, B. Mladenova, Kinetics of the Formation of the Blue Complex $\mathrm{CrO}(\mathrm{O} 2) 2$ Formed by Dichromate and $\mathrm{H} 2 \mathrm{O} 2$ in Acid Solutions. A Stopped-Flow Investigation Using Rapid-Scan UV-VIS Detection, Monatshefte Für Chemie. 133 (2002) 1363-1372. https://doi.org/10.1007/s00706002-0488-5.

[37] A multitechnique characterization of dealuminated mordenites, Journal of Catalysis. 110 (1988) 82-95. https://doi.org/10.1016/0021-9517(88)90299-0.

[38] A. Guyot, H. Charcosset, A. Revillon, G. Vuillaume, Interaction between Chromium Oxide and Its Silica-Alumina Support and Activity of the Resulting Polymerization Catalyst, Journal of Macromolecular Science: Part A - Chemistry. 2 (1968) 135-152. https://doi.org/10.1080/00222336808053353. 